\title{
Author correction: Micromotor-enabled active drug delivery for in vivo treatment of stomach infection
}

Berta Esteban-Fernández de Ávila1, Pavimol Angsantikul (10 ${ }^{1}$, Jinxing Li ${ }^{1}$, Miguel Angel Lopez-Ramirez ${ }^{1}$, Doris E. Ramírez-Herrera1', Soracha Thamphiwatana1, Chuanrui Chen', Jorge Delezuk', Richard Samakapiruk1, Valentin Ramez ${ }^{1}$ Marygorret Obonyo ${ }^{2}$, Liangfang Zhang (i) ${ }^{1} \&$ Joseph Wang ${ }^{1}$

Nature Communications 8:272 doi:10.1038/s41467-017-00309-w; Article published online 16 August 2017

Marygorret Obonyo, who provided the H. pylori SS1 strain for this work and participated in the design of $H$. pylori infection studies, was inadvertently omitted from the author list. This has now been corrected in both the PDF and HTML versions of the Article.

Published online: 31 October 2017

\begin{abstract}
(c) (i) Open Access This article is licensed under a Creative Commons Attribution 4.0 International License, which permits use, sharing, adaptation, distribution and reproduction in any medium or format, as long as you give appropriate credit to the original author(s) and the source, provide a link to the Creative Commons license, and indicate if changes were made. The images or other third party material in this article are included in the article's Creative Commons license, unless indicated otherwise in a credit line to the material. If material is not included in the article's Creative Commons license and your intended use is not permitted by statutory regulation or exceeds the permitted use, you will need to obtain permission directly from the copyright holder. To view a copy of this license, visit http://creativecommons.org/licenses/by/4.0/.
\end{abstract}

(C) The Author(s) 2017

\footnotetext{
${ }^{1}$ Department of NanoEngineering, University of California San Diego, La Jolla, CA 92093, USA. ${ }^{2}$ Department of Medicine, University of California San Diego, La Jolla, CA 92093, USA. Berta Esteban-Fernández de Ávila, Pavimol Angsantikul and Jinxing Li contributed equally to this work. Correspondence and requests for materials should be addressed to L.Z. (email: zhang@ucsd.edu) or to J.W. (email: josephwang@ucsd.edu)
} 